\title{
Addition of clonidine or lignocaine to ropivacaine for supraclavicular brachial plexus block: a comparative study
}

\author{
Bhatia Rohan ${ }^{1}$, mBBs, MD, Payal Yashwant Singh ${ }^{1}$, MBBs, MD, Khurana Gurjeet ${ }^{1}$, MBBS, MD
}

INTRODUCTION Clonidine is used with local anaesthetics to improve analgesia. However, the improvement conferred when clonidine is used together with ropivacaine is controversial. Thus, the present study aimed to evaluate the improvement in analgesia when clonidine is used together with ropivacaine for supraclavicular brachial plexus block.

METHODS This was a prospective, randomised, double-blind controlled study. A total of 75 patients who were scheduled to undergo supraclavicular block were randomly assigned into three groups (i.e. clonidine, lignocaine and control groups) of 25 . Patients in all three groups received $20 \mathrm{~mL}$ of $0.75 \%$ ropivacaine. In addition to that, patients in the clonidine group received $1 \mathrm{~mL}$ of clonidine $(150 \mu \mathrm{g})$ plus $9 \mathrm{~mL}$ of saline, patients in the lignocaine group received $10 \mathrm{~mL}$ of $2 \%$ lignocaine with adrenaline $(1: 200,000)$, and patients in the control group received $10 \mathrm{~mL}$ of saline. The characteristics of anaesthesia and analgesia for these three groups were assessed.

RESULTS The addition of $2 \%$ lignocaine with adrenaline to ropivacaine led to earlier onset of the sensory block (by 4.88 mins), but no increase in the duration of analgesia when compared to analgesia using ropivacaine alone. The addition of clonidine to ropivacaine led to earlier onset of sensory and motor blocks (by 2.88 mins and 3.28 mins, respectively), as well as an increased duration of sensory and motor blocks (by 222.64 mins and 192.92 mins, respectively) when compared to analgesia using ropivacaine alone. The total duration of analgesia was increased by 208.24 mins with clonidine when compared to analgesia using ropivacaine alone. There were no significant differences in sedation score and no side effects in all three groups.

CONCLUSION When compared to the use of ropivacaine alone, the addition of $150 \mu \mathrm{g}$ clonidine to ropivacaine for brachial plexus block achieved earlier analgesic onset and improved duration of analgesia, without unwanted side effects.

Keywords: anaesthetic technique, clonidine, duration of analgesia, ropivacaine, supraclavicular brachial plexus block

\section{INTRODUCTION}

Brachial plexus blocks remain a well-accepted anaesthetic technique for surgical procedures on the upper limbs. Clonidine, when used as an adjuvant to intermediate or long-acting local anaesthetics, improves the duration of analgesia and anaesthesia in brachial plexus or peripheral nerve blocks. ${ }^{(1,2)}$ Although ropivacaine is a chemical congener of bupivacaine, the effect of clonidine when added to ropivacaine for brachial plexus block remains controversial, with some studies not supporting the analgesia-enhancing effects of clonidine as an adjuvant to ropivacaine. ${ }^{(3-5)}$ However, in these studies, the blocks were performed using an axillary approach. To the best of our knowledge, no previous study has combined the use of clonidine and ropivacaine for supraclavicular blocks. As the supraclavicular approach may have many advantages over the axillary approach (e.g. early onset, and complete and predictable anaesthesia for the entire upper extremity), ${ }^{\left({ }^{6}\right)}$ the present study was designed to evaluate the onset and duration of anaesthesia, analgesia and sensory/motor blockade following supraclavicular brachial plexus blocks in which clonidine was used as an adjuvant to ropivacaine.

\section{METHODS}

Following approval from the local ethics committee, a prospective, randomised, double-blind controlled trial was designed. Written informed consent was obtained from all patients selected for inclusion in the present study. The study included a total of 75 patients, who were aged $\geq 18$ years, weighed $\geq 40 \mathrm{~kg}$, had ASA (American Society of Anesthesiologists) physical status I-III, and were scheduled to undergo elective surgery on the upper extremity. Patients who refused to participate in the present study, had neurological diseases of the upper extremities, had contraindications to regional anaesthesia and any of the study drugs (i.e. clonidine, ropivacaine or lignocaine), and/or were pregnant or lactating, were excluded from the study.

Patients were randomly assigned to any one of three groups (i.e. either the clonidine, lignocaine or control group); each group had a total of 25 patients. The anaesthetist who performed the randomisation also prepared the drug solutions, but was otherwise not involved in the study. In the preoperative area, an intravenous (IV) line was established and IV midazolam 1-2 mg was administered to all 75 patients. The

Department of Anaesthesiology, Himalayan Institute of Medical Sciences, Uttarakhand, India

Correspondence: Dr Y S Payal, Associate Professor, Department of Anaesthesiology, Himalayan Institute of Medical Sciences, Swami Ram Nagar, Dehradun, Uttarakhand 248140, India. dryspayal05@gmail.com 
patients were then moved to the operating room, where their heart rate, respiratory rate, oxygen saturation and noninvasive blood pressure were monitored. The supraclavicular blocks were performed by an anaesthetist who was unaware of the composition of the local anaesthetic solution administered, as per the method described by Franco. ${ }^{(7)}$ A 22-gauge $50-\mathrm{mm}$ needle (Stimuplex ${ }^{\circledR} \mathrm{A}$ 50; B.Braun, Melsungen, Germany) connected to a nerve stimulator (NM-20 ${ }^{\circledR}$; INMED Equipments Pvt Ltd, Vadodara, India) was inserted at an initial current output of $1.0 \mathrm{~mA}, 0.1 \mathrm{~ms}$ and $2 \mathrm{~Hz}$ frequency, which was gradually reduced to $0.2-0.5 \mathrm{~mA}$. The local anaesthetic solution $(30 \mathrm{~mL})$ was injected into all patients following negative aspiration, while maintaining the visible twitch of muscle groups in the forearm.

Patients in the clonidine group $\left(\mathrm{R}_{\mathrm{C}}\right)$ received $20 \mathrm{~mL} 0.75 \%$ ropivacaine with $9 \mathrm{~mL} 0.9 \%$ saline and $1 \mathrm{~mL}$ clonidine $(150 \mu \mathrm{g})$. The patients in the lignocaine group $\left(\mathrm{R}_{\mathrm{L}}\right)$ received $20 \mathrm{~mL}$ 0.75\% ropivacaine with $10 \mathrm{~mL} 2 \%$ lignocaine with adrenaline $(1: 200,000)$. Patients in the control group $\left(R_{\mathrm{O}}\right)$ were given $20 \mathrm{~mL} 0.75 \%$ ropivacaine with $10 \mathrm{~mL}$ 0.9\% saline. The final concentration of ropivacaine in the local anaesthetic solution was maintained at $0.5 \%$.

Completion of injection was considered as time-0, and the sensory block was evaluated using the pin prick method ${ }^{(8)}$ (score 0: sharp pain; score 1: touch sensation only; score 2: no sensation) at 2-min intervals from time-0 until complete sensory block was achieved. Onset time of sensory block (OTSB) was defined as the time interval (in mins) from time-0 to the time the sensory block started to be detected (i.e. score $=1$ ). Time for complete sensory block (TCSB) was the time interval (in mins) from time- 0 to the time complete sensory block was achieved (i.e. score $=2$ ). Total duration of sensory block (TDSB) was the time interval (in mins) from the time complete sensory block was achieved to the time the score was $<2$. Total duration of analgesia (TDA) was taken as the time interval (in mins) between the time complete sensory block was achieved and the time of first analgesic request.

Motor block was evaluated using the Modified Bromage Scale ${ }^{(9)}$ (score 0: able to raise the extended arm at $90^{\circ}$ for a full $2 \mathrm{~s}$; score 1: able to flex the elbow and move the fingers, but unable to raise the extended arm; score 2: unable to flex the elbow, but able to move the fingers; score 3: unable to move the arm, elbow and fingers). Findings were recorded every 2 mins from time-0 until the complete loss of motor power. As with the sensory block, the onset time of motor block (OTMB) was defined as the time interval (in mins) from time- 0 to the time the motor block started to be detected (i.e. score $\geq 1$ ). Time for complete motor block (TCMB) was the time interval (in mins) from time- 0 to the time complete motor block was achieved $($ score $=3)$. Total duration of motor block $($ TDMB) was the time interval (in mins) between the time complete motor block was achieved and the time when the score was $<3$. Adequacy of the block was evaluated using the Allis clamp test. ${ }^{(9)}$
Heart rate, arterial blood pressure (systolic, diastolic and mean measurements) and arterial oxygen saturation were recorded every 5 mins from time-0 until the completion of surgery, and thereafter every 30 mins until recovery. Hypotension, which was defined as a decrease in mean arterial pressure of more than $25 \%$ from baseline, was treated with ephedrine $5 \mathrm{mg}$ IV bolus. Clinically significant bradycardia $(<45$ bpm) was treated with IV atropine $0.6 \mathrm{mg}$. Mild postoperative pain was treated with six-hourly IV paracetamol $1 \mathrm{~g}$, while fentanyl $100 \mu \mathrm{g}$ was added for moderate-to-severe pain. All patients were monitored until complete recession of motor and sensory blocks; the time to first analgesic requirement and the total analgesic dose administered were noted.

Sedation was assessed every 5 mins from time- 0 until the end of surgery, and every 30 mins thereafter, with the use of the Sedation Scale ${ }^{(10)}$ (1: awakened and alert; 2: sedated, but responding to verbal stimulus; 3 : sedated, but responding to mild physical stimulus; 4: sedated, but responding to moderate or strong physical stimulus; 5: not arousable).

The sample size of the present study was determined according to the methodology described in previous studies. ${ }^{(11,12)}$ Results were presented as mean \pm standard deviation for parametric data and as percentages for nonparametric data. Data was analysed using standard statistical test softwares such as Microsoft Office Excel 2007 (Microsoft, Redmond, WA, USA) and IBM SPSS Statistics version 19.0 (IBM Corp, Armonk, NY, USA). Kruskal-Wallis $\mathrm{H}$ test was used to compare the data among the three patient groups and unpaired $t$-test was used to determine significant differences between the groups. A p-value of $<0.05$ was considered statistically significant and a $p$-value of $<0.001$ was taken to be highly significant.

\section{RESULTS}

Among the patients in the $R_{C}, R_{L}$ and $R_{O}$ groups, no significant differences were observed with respect to the following factors: age, gender, height, weight and duration of surgery (Table I). No instances of failed blocks necessitating the administration of general anaesthesia were noted in any of the three patient groups.

The onset of sensory and motor blocks was earliest in the $\mathrm{R}_{\mathrm{L}}$ group (OTSB $3.84 \pm 0.80$ mins; OTMB $5.76 \pm 1.05$ mins) followed by the $R_{C}$ group (OTSB $5.84 \pm 0.55$ mins; OTMB $6.80 \pm 1.00$ mins); onset was significantly delayed in the $R_{O}$ group (i.e. the control group; OTSB $8.72 \pm 1.13$ mins; OTMB $10.08 \pm 0.90$ mins $)(p<0.001)$. Similarly, sensory and motor blocks were achieved in a shorter duration of time in the $R_{L}$ group (TCSB $9.52 \pm 1.33$ mins; TCMB $14.32 \pm 0.94$ mins) compared to the $R_{C}$ group (TCSB $11.80 \pm 1.28$ mins; TCMB $17.12 \pm 1.30$ mins). The achievement of sensory and motor blocks was significantly delayed in the $R_{O}$ group (TCSB $15.12 \pm 1.42$ mins; TCMB $19.52 \pm 0.87$ mins $)(p<0.001)$. The total durations of the sensory and motor blocks were significantly longer in the $R_{C}$ group (TDSB $450.08 \pm 54.45$ mins; 
Table I. Characteristics of the patients who underwent elective surgery of the upper extremity $(\mathrm{n}=75)$.

\begin{tabular}{|c|c|c|c|c|}
\hline \multirow[t]{2}{*}{ Variable } & \multicolumn{3}{|c|}{ Mean \pm SD } & \multirow[t]{2}{*}{ p-value } \\
\hline & $R_{0}$ group $(n=25)$ & $R_{L}$ group $(n=25)$ & $R_{c}$ group $(n=25)$ & \\
\hline Age (yrs) & $38.20 \pm 15.74$ & $42.64 \pm 16.39$ & $39.04 \pm 16.47$ & 0.589 \\
\hline $\begin{array}{l}\text { Gender* } \\
\text { Male } \\
\text { Female }\end{array}$ & $\begin{array}{r}20(80.0) \\
5(20.0)\end{array}$ & $\begin{array}{r}18(72.0) \\
7(28.0)\end{array}$ & $\begin{array}{r}19(76.0) \\
6(24.0)\end{array}$ & 0.803 \\
\hline Height (cm) & $161.02 \pm 5.95$ & $162.78 \pm 7.42$ & $164.42 \pm 7.41$ & 0.265 \\
\hline Weight (kg) & $60.10 \pm 7.58$ & $60.56 \pm 10.49$ & $62.96 \pm 11.00$ & 0.651 \\
\hline Duration of surgery (mins) & $46.32 \pm 38.03$ & $58.52 \pm 34.18$ & $83.88 \pm 51.08$ & 0.052 \\
\hline \multicolumn{5}{|l|}{ Duration of block (mins) } \\
\hline OTSB & $8.72 \pm 1.13$ & $3.84 \pm 0.80$ & $5.84 \pm 0.55$ & $<0.001^{+}$ \\
\hline OTMB & $10.08 \pm 0.90$ & $5.76 \pm 1.05$ & $6.80 \pm 1.00$ & $<0.001^{+}$ \\
\hline TCSB & $15.12 \pm 1.42$ & $9.52 \pm 1.33$ & $11.80 \pm 1.28$ & $<0.001^{+}$ \\
\hline TCMB & $19.52 \pm 0.87$ & $14.32 \pm 0.94$ & $17.12 \pm 1.30$ & $<0.001^{+}$ \\
\hline TDMB & $172.64 \pm 40.86$ & $183.76 \pm 26.73$ & $368.56 \pm 59.68$ & $<0.001^{+}$ \\
\hline TDA & $297.04 \pm 24.80$ & $298.04 \pm 27.06$ & $505.28 \pm 48.39$ & $<0.001^{+}$ \\
\hline
\end{tabular}

${ }^{\star}$ Data is presented as no. (\%). ${ }^{\dagger}$ Highly significant (i.e. $p<0.001$ ).

OTMB: onset time of motor block; OTSB: onset time of sensory block; $R_{C}$ group: group administered ropivacaine + clonidine; $R_{L}$ group: group administered ropivacaine + lignocaine; $R_{O}$ group: group administered ropivacaine + saline (i.e. control group); SD: standard deviation; TCMB: time for complete motor block; TCSB: time for complete sensory block; TDA: total duration of analgesia; TDMB: total duration of motor block; TDSB: total duration of sensory block

TDMB $365.56 \pm 59.68$ mins) than in the $R_{L}$ group (TDSB $238.04 \pm 35.10$ mins; TDMB $183.76 \pm 26.73$ mins) and $\mathrm{R}^{\mathrm{O}}$ group (TDSB $227.44 \pm 36.27$ mins; TDMB $172.64 \pm$ 40.86 mins) $(p<0.001)$. TDA was also significantly longer (over 1.5 times) in the $R_{C}$ group $(505.28 \pm 48.39$ mins) than in the $R_{L}$ group $(298.04 \pm 27.06$ mins $)$ and $R_{O}$ group $(297.04 \pm$ 24.80 mins) $(p<0.001)$.

In the present study, the addition of clonidine to ropivacaine was not found to cause any significant increase in the incidences of hypotension or bradycardia. Sedation, a major side effect with the use of clonidine, was not seen in any of our patients. Three patients (two from the $\mathrm{R}_{\mathrm{O}}$ group and one from the $R_{C}$ group) had vessel injury, which was managed with pressure application. No haematoma formation was noted postoperatively.

\section{DISCUSSION}

In the present study, we found that the addition of $150 \mu \mathrm{g}$ clonidine to $30 \mathrm{~mL}$ of $0.5 \%$ ropivacaine $\left(\mathrm{R}_{\mathrm{C}}\right.$ group) led to an earlier onset of sensory and motor blocks, as well as an increased duration of analgesia, when compared to the use of $0.5 \%$ ropivacaine alone $\left(\mathrm{R}_{\mathrm{O}} /\right.$ control group). The addition of $2 \%$ lignocaine with adrenaline to $0.5 \%$ ropivacaine ( $R_{L}$ group) led to the earliest onset of sensory and motor blocks among the three groups; however, this was without a significant improvement in the duration of analgesia. Our findings are in agreement with previous systematic reviews, which demonstrated that clonidine, when used as an adjuvant to local anaesthetics, improves anaesthesia and the analgesic duration of the local anaesthetic block. ${ }^{(1,2)}$

The early onset of sensory and motor blocks in the $R_{L}$ group of the present study is likely related to the pharmacological properties of lignocaine. In the $R_{C}$ group, the combined vasoconstrictive property of clonidine $\mathrm{e}^{(13)}$ and ropivacaine $\mathrm{e}^{(14)}$ may have led to the greater availability of these drugs at the vicinity of the nerve plexus; this may possibly account for the earlier onset of sensory and motor blocks seen in the $R_{C}$ group, as compared to the $R_{O}$ group. Studies have also reported that clonidine is effective in blocking the conduction of $\mathrm{A} \delta$-fibres and $\mathrm{C}$-fibres, and that it intensifies the conduction block of local anaesthetics. ${ }^{(15,16)}$ Although a faster onset could have been achieved with the use of higher concentrations of ropivacaine, the concentration of ropivacaine was restricted to $0.5 \%$ in the present study because increasing concentrations of ropivacaine were not found to affect the duration of postoperative analgesia in previous studies. ${ }^{(17)}$

In the present study, the blocks were performed via the supraclavicular approach instead of the axillary approach, as the former was associated with faster onset ${ }^{(11)}$ and many other advantages. ${ }^{(6)}$ It should be noted that the brachial plexus is not surrounded by a 'sheath', instead it lies in a tissue plane closely surrounded by the clavicle, scapula, chest wall and humerus. ${ }^{(18)}$ Elements of the brachial plexus (i.e. its trunks, divisions and cords) interlace and interlink at the supraclavicular level. As these elements are closer to each other at the supraclavicular level, the plexus is more compact at this level than at the axillary level. This means that, at the supraclavicular level, the connective tissues containing these nerves allow a more even spread of the drug solution, ${ }^{(19)}$ making the use of 30-mL drug solutions sufficient and as effective as 40-mL drug solutions, which has been used in other studies for axillary blocks. $^{(11,12,20,22)}$

Improvement in the duration of analgesia following the addition of clonidine to local anaesthetics has been reported in earlier studies. ${ }^{(11,12,20-22)}$ Antinociception due to the action of adrenoceptors (e.g. clonidine on $\alpha 2$ receptors) is well documented in clinical trials conducted on animals and humans. ${ }^{(23)}$ The analgesic property of clonidine is attributed 
to its greater affinity for the $\alpha 2$ receptors that are located on the brainstem nuclei, including those on the locus ceruleus and those on the neurons in the superficial laminae of the spinal cord and primary afferent terminals. A decrease in the activity of these nuclei by $\alpha 2$ agonists supports the possibility of analgesic action at the spinal and supraspinal sites. ${ }^{(3,24)}$ Although it is unlikely that the spinal and supraspinal effect is the mechanism that prolongs the analgesic effect of clonidine deposited at peripheral sites, ${ }^{(3)}$ a central analgesic effect that results from the systemic absorption of clonidine cannot be excluded. Sia and Lepri demonstrated that clonidine does not provide postoperative analgesia when administered as the sole analgesic agent, ${ }^{(25)}$ suggesting that synergistic activity is more likely the mechanism for the prolonged analgesic duration observed with the use of clonidine. The direct action of clonidine, independent of its action on $\alpha 2$ receptor nerve fibre conduction, has been demonstrated in some studies, $16,26,27)$ indicating another possible mechanism for its action as a local anaesthetic additive. Hutschala et al have postulated that the effect of clonidine is local. ${ }^{(28)}$

The mechanism of action for the prolonged duration of analgesia observed when clonidine is used as an adjuvant to ropivacaine has been reported to be multifactorial and complex. ${ }^{(11)}$ While the synergistic effects of clonidine, or lignocaine, with ropivacaine were evident in the $R_{C}$ and $R_{L}$ groups in our study, we were unable to draw meaningful inferences regarding the underlying mechanisms involved from the available data, as the present study was not designed to elucidate the mechanism for prolongation of analgesia.

In the present study, the addition of $2 \%$ lignocaine with adrenaline to $0.5 \%$ ropivacaine was not found to improve the duration of analgesia, as ropivacaine is known to have intrinsic vasoconstrictive properties. ${ }^{(14)}$ The prolonged duration of the motor block in the $R_{C}$ group in our study is in agreement with the findings of a study by El Saied et al. ${ }^{(11)}$ We did not observe any adverse effects such as sedation, arterial hypotension or bradycardia in our patients. The dose of clonidine $(150 \mu \mathrm{g})$ used appeared to have minimal or no adverse effects among our patients, similar to the findings of El Saied et al.(11)

To conclude, the addition of clonidine to ropivacaine for analgesia was found to be safe and effective in the present study. In the clinical setting, the addition of clonidine to ropivacaine during supraclavicular brachial plexus block would achieve early operating conditions and prolonged analgesia. In contrast, the addition of lignocaine to ropivacaine resulted only in earlier onset of sensory and motor blocks, without improvement in the duration of analgesia.

\section{REFERENCES}

1. Pöpping DM, Elia $N$, Marret $E$, Wenk $M$, Tramèr $M R$. Clonidine as an adjuvant to local anesthetics for peripheral nerve and plexus blocks: a meta-analysis of randomized trials Anesthesiology 2009; 111:406-15.

2. McCartney CJ, Duggan E, Apatu E. Should we add clonidine to local anesthetic for peripheral nerve blockade? A qualitative systematic review of the literature. Reg Anesth Pain Med 2007; 32:330-8.

3. Duma A, Urbanek B, Sitzwohl C, et al. Clonidine as an adjuvant to local anaesthetic axillary brachial plexus block: a randomized, controlled study. Br J Anaesth 2005; 94:112-6.

4. Erlacher W, Schuschnig C, Koinig H, et al. Clonidine as adjuvant for mepivacaine, ropivacaine and bupivacaine in axillary, perivascular brachial plexus block. Can J Anaesth 2001; 48:522-5.

5. Esteves S, Sá P, Figueiredo D, Pèrez Souto A. [Duration and quality of postoperative analgesia after brachial plexus block for shoulder surgery: ropivacaine $0.5 \%$ versus ropivacaine $0.5 \%$ plus clonidine]. Rev Esp Anestesiol Reanim 2002; 49:302-5. Spanish.

6. Moore DC, Bridenbaugh LD, Eather KF. Block of the upper extremity. Arch Surg 1965; 90:68-72.

7. Franco CD. Manual of regional anesthesia [online]. Available from http:// www.cookcountyregional.com/Chapter6.pdf. Accessed July 26, 2013.

8. Wakhlo R, Gupta V, Raina A, Gupta SD, Lahori VU. Supraclavicular Plexus Block: Effect of Adding Tramadol or Butorphanol as an Adjuncts to Local Anaesthetic on Motor and Sensory Block and duration of Post-operative Analgesia. J Anaesth Clin Pharmacol 2009; 25:17-20.

9. Cline E, Franz D, Polley RD, et al. Analgesia and effectiveness of levobupivacaine compared with ropivacaine in patients undergoing an axillary brachial plexus block. AANA Journal 2004; 72:339-45.

10. Singh SP, Singh V, Kaushal D, Jafa S. Effect of alkalinized bupivacaine and fentanyl mixture in supraclavicular brachial plexus block-A randomised double blind controlled trial. J Anaesth Clin Pharmacol 2009; 25:25-8.

11. El Saied AH, Steyn MP, Ansermino JM. Clonidine prolongs the effect of ropivacaine for axillary brachial plexus blockade. Can J Anaesth 2000; 47:962-7.

12. Eledjam JJ, Deschodt J, Viel EJ, et al. Brachial plexus block with bupivacaine: effects of added alpha-adrenergic agonists: comparison between clonidine and epinephrine. Can J Anaesth 1991; 38:870-5.

13. Ishiyama T, Dohi S, lida H. The vascular effects of topical and intravenous alpha2-adrenoceptor agonist clonidine on canine pial microcirculation. Anesth Analg 1998; 86:766-72.

14. McClure JH. Ropivacaine - review. Br J Anaesth 1996; 76:300-7.

15. Gaumann DM, Brunet PC, Jirounek P. Clonidine enhances the effects of lidocaine on C-fiber action potential. Anesth Analg 1992; 74:719-25.

16. Butterworth JF 5th, Strichartz GR. The alpha 2-adrenergic agonists clonidine and guanfacine produce tonic and phasic block of conduction in rat sciatic nerve fibers. Anesth Analg 1993; 76:295-301.

17. Casati A, Fanelli G, Aldegheri G, Berti M, Colnaghi E, Cedrati V. Interscalene brachial plexus anaesthesia with $0.5 \%, 0.75 \%$ or $1 \%$ ropivacaine: a doubleblind comparison with 2\% mepivacaine. Br J Anaesth 1999; 83:872-5.

18. Cornish PB, Leaper C. The sheath of the brachial plexus: fact or fiction? Anesthesiology 2006; 105:563-5.

19. Klaastad Ø, Smedby O, Thompson GE, et al. Distribution of local anesthetic in axillary brachial plexus block: a clinical and magnetic resonance imaging study. Anesthesiology 2002; 96:1315-24.

20. Singelyn FJ, Gouverneur JM, Robert A. A minimum dose of clonidine added to mepivacaine prolongs the duration of anesthesia and analgesia after axillary brachial plexus block. Anesth Analg 1996; 83:1046-50.

21. Iohom G, Machmachi A, Diarra DP, et al. The effects of clonidine added to mepivacaine for paronychia surgery under axillary brachial plexus block. Anesth Analg 2005; 100:1179-83.

22. Chakraborty S, Chakrabarti J, Mandal MC, Hazra A, Das S. Effect of clonidine as adjuvant in bupivacaine-induced supraclavicular brachial plexus block: A randomized controlled trial. Indian J Pharmacol 2010; 42:74-7.

23. Hayashi Y, Maze M. Alpha 2 adrenoceptor agonists and anaesthesia. $\mathrm{Br}$ J Anaesth 1993; 71:108-18.

24. Guo TZ, Jiang JY, Buttermann AE, Maze M. Dexmedetomidine injection into the locus ceruleus produces antinociception. Anesthesiology 1996; 84:873-81.

25. Sia S, Lepri A. Clonidine administered as an axillary block does not affect postoperative pain when given as the sole analgesic. Anesth Analg 1999; 88:1109-2.

26. Gaumann DM, Brunet PC, Jirounek P. Hyperpolarizing after potentials in $C$ fibers and local anesthetic effects of clonidine and lidocaine. Pharmacology 1994; 48:21-9.

27. Leem JW, Choi Y, Han SM, et al. Conduction block by clonidine is not mediated by alpha2-adrenergic receptors in rat sciatic nerve fibers. Reg Anesth Pain Med 2000; 25:620-5.

28. Hutschala D, Mascher H, Schmetterer L, et al. Clonidine added to bupivacaine enhances and prolongs analgesia after brachial plexus block via a local mechanism in healthy volunteers. Eur J Anaesthesiol 2004; 21:198-204. 